\title{
STIFFNESS OF CARPENTRY CONNECTIONS - NUMERICAL MODELLING VS. EXPERIMENTAL TEST
}

\author{
Miloš KEKELIAK ${ }^{1}$, Jozef GOCÁL ${ }^{1,{ }^{*}}$, Josef VIČAN ${ }^{1}$ \\ ${ }^{1}$ Department of Structures and Bridges, Faculty of Civil Engineering, University of Žilina, Univerzitná \\ 1, 01026 Žilina, Slovakia. \\ corresponding author: jozef.gocal@fstav.uniza.sk, +421-4-1513 5655.
}

\begin{abstract}
In this paper, numerical modelling of the traditional carpentry connection with mortise and tenon is presented. Numerical modelling is focused on its stiffness and the results are compared to results of experimental tests carried out by (Feio, 2005) [6]. To consider soft behaviour of wood in carpentry connections, which are related to its surface roughness and geometrical accuracy of the contact surfaces, the characteristics of the normal contact stiffness, determined experimentally, are introduced in the numerical model. Parametric study by means of numerical modelling with regard to the sensitivity of connection stiffness to contact stiffness is presented. Based on the study results, in conclusion there are presented relevant differences between the results of numerical modelling and experimental tests (Feio, 2005) [6].
\end{abstract}

\author{
Keywords: \\ Timber structures; \\ Carpentry connections; \\ Joint stiffness; \\ Normal contact stiffness.
}

\section{Introduction}

The common attribute of carpentry connections is the contact interface between two or more timber members. Additional fixation elements like steel straps or stirrups can be present in carpentry connection, which can increase the performance of connection, secure stability of member position or it can also improve the distribution of forces. Considering the non-rigid, thus the elastic loaddeformation behavior of carpentry connection, the wood zone near the contact and the contact interface between wood members arise as the subject of interest in terms of structural behavior of carpentry connection. This part of the connection directly relates with distribution of acting forces and their transmission from one timber member to another.

Current standard for design of timber structures, Eurocode 5 [1] provides general rules and recommendations for the analysis and verification of structural response regarding the serviceability and the ultimate limit state. The effect of deformations of the connections shall be taken into account for the calculation of internal forces in the structure or in part of it. According to standard [1] "The influence of deformations in the connections should be taken into account through their stiffness (rotational or translational for instance) or through prescribed slip values as a function of the load level in the connection". The forces and the moments between the members determined by the global structural analysis shall be used to verify the load-carrying capacity of the connections. The deformation of the connection shall be compatible with that assumed in the global analysis.

Carpentry connections do not behave as rotationally rigid, but neither as a perfect hinges [2], [3], [4]. The necessity to introduce in models beside the rotational stiffness also the axial stiffness was presented by [5]. Numerical modelling presented by [6] has shown that the analysis with assumption of an infinite stiffness of the contact interface between wood members of carpentry connection results in too stiff response. In order to analyze the stiffness of carpentry joint and the sensitivity of calculated results to stiffness of the contact interface, a parametric study by means of numerical modelling was done and the results are presented in the article.

\section{Numerical modelling}

The analysis is focused on the joint stiffness calculation using the experimental data evaluated during the experimental investigation presented in [7]. In the following analysis a mortise and tenon 
joint tested by (Feio) [6] is presented. Geometry of the carpentry joint is adopted from [6] and [7] and it is described in Fig. 1.

The position of the LVDT transducer (linear variable differential transformers) used for measuring of the vertical displacement was in the third of the brace length. Displacements of carpentry joint calculated in the numerical model correspond to vertical displacements of the points $P_{1}$ and $P_{2}$ located on the sides of brace and rafter as shown in Fig. 1.

The FEA software package ANSYS [9] have been used for analysis. Numerical model description including the position of points $\mathrm{P}_{1}$ and $\mathrm{P}_{2}$ is shown in Fig. 2. Only one half of the geometry is modelled due to the joint symmetry. Steel plates are $20 \mathrm{~mm}$ thick and they are constrained in all directions at the bottom side. Two solid wood members are modelled using the SOLID186 and SOLID 187 finite elements. The load is applied as pressure on the top surface of the brace member. The elastic support in horizontal direction is modelled according to [6] with the stiffness equal to $10^{6} \mathrm{~N} \cdot \mathrm{m}^{-1}$.

The orthotropic elastic material model is adopted to define of the wood material behavior. Mechanical orthotropic are applied for wood members considering their local coordinate systems as presented in Fig. 2. In order to compare the wood specimens tested by [6] with different data sources of wood species Castanea sativa (Mill.) (Chestnut wood) and to adopt the missing shear modulus for RT-plane, a search for mechanical properties has been performed and the wood properties are presented in Table 1. The mechanical properties adopted in the numerical model are presented in Table 2.

Specimen orientation: $\mathrm{H}$ - Horizontal direction V - Vertical direction

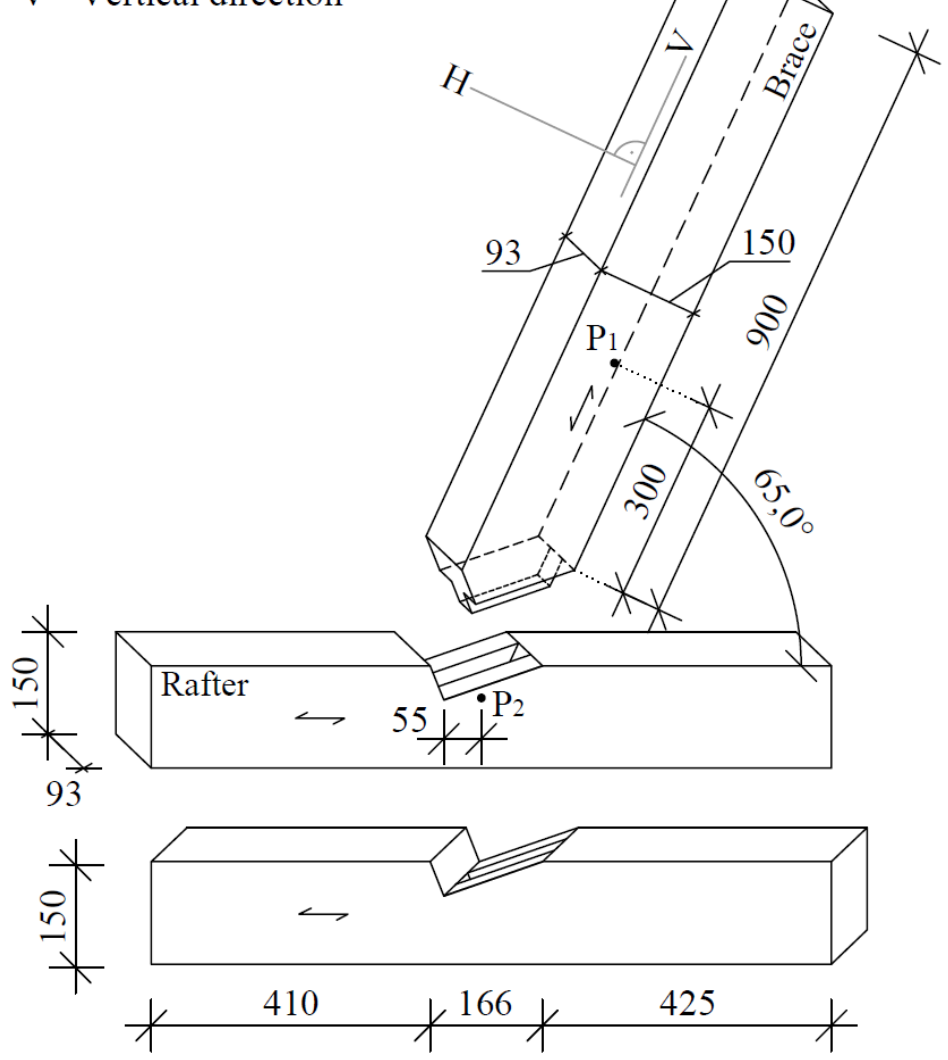

Fig. 1: Carpentry joint, assembly of wood members and their dimensions in $\mathrm{mm}$. 


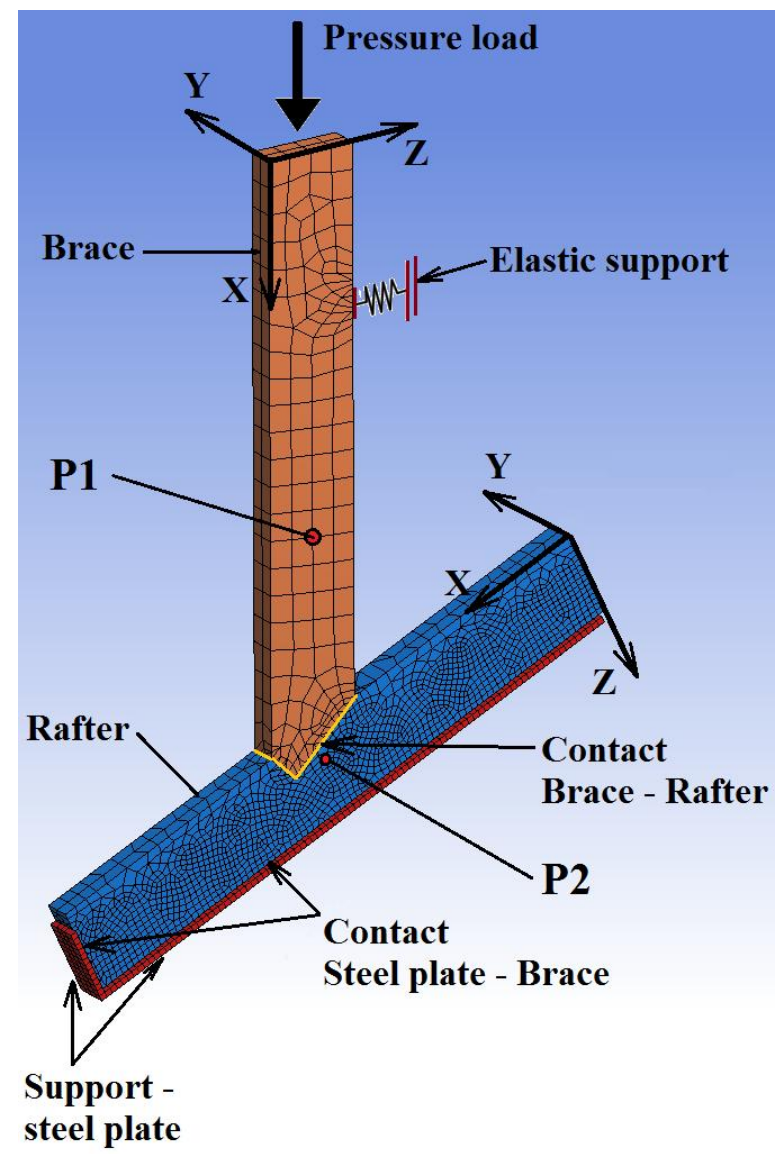

Fig. 2: Finite element model visualisation.

Table 1: Mechanical properties of Chestnut wood, Castanea sativa (Mill.).

\begin{tabular}{|c|c|c|c|c|c|}
\hline \multirow{2}{*}{\multicolumn{2}{|c|}{$\begin{array}{c}\text { Mechanical } \\
\text { property }\end{array}$}} & \multicolumn{4}{|c|}{ Reference } \\
\hline & & [6] & [15] & [16] & {$[17]^{c)}$} \\
\hline$E_{\mathrm{L}}$ & $(\mathrm{MPa})$ & 8500 & 13000 & 12400 & 10000 \\
\hline$E_{\mathrm{R}}$ & (MPa) & $800^{\text {a) }}$ & $1400^{\text {a) }}$ & & $670^{\text {a) }}$ \\
\hline$E_{\mathrm{T}}$ & $(\mathrm{MPa})$ & $800^{\text {a) }}$ & $1400^{\text {a) }}$ & & $670^{\text {a) }}$ \\
\hline$U_{L R}$ & $(-)$ & 0.31 & & & \\
\hline$U_{\mathrm{RT}}$ & $(-)$ & 0.71 & & & \\
\hline$U_{L T}$ & $(-)$ & 0.31 & & & \\
\hline$G_{L R}$ & (MPa) & $1500^{\text {a) }}$ & $810^{\text {a) }}$ & $1240^{b)}$ & $620^{\text {a) }}$ \\
\hline$G_{R T}$ & (MPa) & & 65 & & \\
\hline$G_{L T}$ & $(\mathrm{MPa})$ & $1500^{\text {a) }}$ & $810^{\text {a) }}$ & $1240^{b)}$ & $620^{\text {a) }}$ \\
\hline$\rho_{\mathrm{m}}$ & $\left(\mathrm{kg} \cdot \mathrm{m}^{-3}\right)$ & 581 & 540 & 583 & 580 \\
\hline
\end{tabular}

a) the same value is adopted for radial and tangential direction

b) averaged value is presented

c) strength class D24 is presented

$E$ - modulus of elasticity, $u$-Poisson's ratio, $G$ - shear modulus, $\rho_{m}-$ mean density, $L$ - longitudinal, $R$ - radial, $T$ - tangential. 
Table 2: Numerical model, mechanical properties of wood.

\begin{tabular}{|c|c|c|c|}
\hline$E_{\mathrm{L}}$ & $E_{X}$ & 8500 & $\mathrm{MPa}$ \\
\hline$E_{\mathrm{R}}$ & $\bar{E}$ & 800 & $\mathrm{MPa}$ \\
\hline$E_{\mathrm{T}}$ & $E_{\mathrm{Z}}$ & 800 & $\mathrm{MPa}$ \\
\hline$U_{\mathrm{LR}}$ & $u_{X Y}$ & 0.31 & $(-)$ \\
\hline$U_{\mathrm{RT}}$ & $u_{Y Z}$ & 0.71 & $(-)$ \\
\hline$U_{L T}$ & $u_{X Z}$ & 0.31 & $(-)$ \\
\hline$G_{L R}$ & $G_{X Y}$ & 1500 & $\mathrm{MPa}$ \\
\hline$G_{\mathrm{RT}}$ & $G_{Y Z}$ & 65 & $\mathrm{MPa}$ \\
\hline$\overline{G_{L T}}$ & $G_{X Z}$ & 1500 & $\mathrm{MPa}$ \\
\hline \multicolumn{4}{|c|}{ (see denotations in Table 1) } \\
\hline
\end{tabular}

\section{Contact modelling}

The connections between the wood-to-wood surfaces and the wood-to-steel plate's surfaces are considered as contact interfaces. The values of the normal contact stiffness adopted for the contact interface in the numerical models were determined experimentally [7]. These characteristics were determined from the compression tests on small wood specimens made of the Spruce wood (Picea Abies Karst.). The characteristics of the contact stiffness are presented in Table 3. The surface-to-surface contact elements CONTA174 and TARGE170 [9] are used for modelling of the contact interfaces. The pure penalty method is used to define the contact, thus the interpenetration of contact surfaces occurs, what represents the displacements in contact zone. The relationship between two contact surfaces is established by contact "spring". The spring stiffness is called the contact stiffness. Formulation of the contact model is presented in Fig. 3 and defined by equation:

$F_{n}=k_{n} \Delta_{n}$

where: $F_{n}$ - normal force (force unit), or normal pressure (force unit/length unit ${ }^{2}$ ),

$\Delta_{\mathrm{n}}$ - penetration in direction normal to the surface (length unit),

$k_{\mathrm{n}}-$ normal contact stiffness (force/length) or (force unit/length unit ${ }^{3}$ ).

The contact interface is modelled as frictionless. The contact stiffness has a unit of Force/Length ${ }^{3}$ for three-dimensional problem, which expresses the relationship between the normal contact pressure and penetration in direction normal to surface.

Preliminary calculations and models have been developed to determine the normal contact stiffness characterizing the "rigid" contact behaviour. Wood specimens tested during the experimental investigation [7] have been modelled in this analysis. The normal contact stiffness equal to 1.5.10 $\mathrm{N} . \mathrm{mm}^{-3}$ was applied for the "rigid" contact behaviour. Difference between displacements of nodes on the steel plate and the wood specimen is $0.006 \mathrm{~mm}$ when the value of the normal contact stiffness equal to $1.5 .10^{4} \mathrm{~N} \cdot \mathrm{mm}^{-3}$ was used.

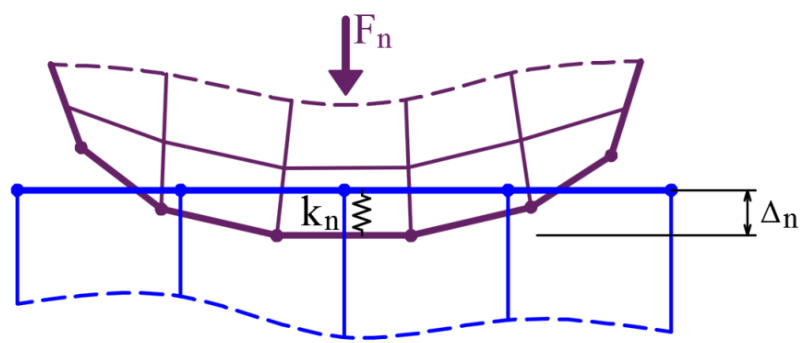

Fig. 3: Numerical modelling, model of contact. 
Table 3: Contact stiffness, results of experimental investigation [7].

\begin{tabular}{|c|c|c|c|c|c|c|c|c|}
\hline Specimen group & \multicolumn{4}{|c|}{$\mathrm{B}$} & \multicolumn{3}{c|}{$\mathrm{c}$} \\
\hline $\begin{array}{c}\text { Load to the grain } \\
\text { orientation }\end{array}$ & \multicolumn{4}{|c|}{ parallel } & \multicolumn{3}{c|}{ perpendicular } \\
\hline Contact & \multicolumn{3}{|c|}{ steel - wood contact } & CoV & \multicolumn{3}{c|}{ steel - wood contact } & CoV \\
\hline Contact stiffness & $K_{\mathrm{C} \|}$ & 114.69 & $\mathrm{~N} \cdot \mathrm{mm}^{-3}$ & 23.7 & $K_{\mathrm{C} \perp}$ & 2.038 & $\mathrm{~N} \cdot \mathrm{mm}^{-3}$ & 19.6 \\
\hline $\begin{array}{c}\text { Modulus of elasticity in } \\
\text { compression }\end{array}$ & $E_{\mathrm{c}, 0}$ & 14038 & $\mathrm{~N} \cdot \mathrm{mm}^{-2}$ & 12.9 & $E_{\mathrm{c}, 90}$ & 410 & $\mathrm{~N} \cdot \mathrm{mm}^{-2}$ & 35.0 \\
\hline $\begin{array}{c}\text { Compression strength } \\
f_{\mathrm{c}, 0}\end{array}$ & 34.77 & $\mathrm{MPa}$ & 9.2 & $f_{\mathrm{c}, 90}$ & 2.361 & $\mathrm{MPa}$ & 5.8 \\
\hline Moisture content & $\omega$ & 11.8 & $\%$ & 3.4 & $\omega$ & 12.1 & $\%$ & 2.6 \\
\hline $\begin{array}{c}\text { Density (mean value at } \\
\omega=12 \%)\end{array}$ & $\rho_{12}$ & 424 & $\mathrm{~kg} \cdot \mathrm{m}^{-3}$ & 3.5 & $\rho_{12}$ & 405 & $\mathrm{~kg} \cdot \mathrm{m}^{-3}$ & 3.9 \\
\hline
\end{tabular}

\section{Parametric study}

The parametric study has been performed to analyse the sensitivity of the joint stiffness on the contact interface stiffness behaviour. Description of the models and parameters of the study are presented in Table 4. In order to consider different surfaces acting in the connection and their contribution to the carpentry joint stiffness, three different types of models have been developed with index numbers 1, 2 and 3 . In the $1^{\text {st }}$ model, only the partial surfaces designated in Fig. 4 as " $1 \mathrm{a}$ " and "2" are taken into account, while the $2^{\text {nd }}$ model includes, in addition to the $1^{\text {st }}$ one, also the partial surfaces " $1 \mathrm{~b}$ " and " 3 ", and finally the $3^{\text {rd }}$ model includes, in addition to the $1^{\text {st }}$ and $2^{\text {nd }}$ one, also the partial surfaces " $1 c$ "and " 4 ". The values of the contact stiffness for parallel and perpendicular to the grain direction were determined experimentally and adopted in the numerical models $\left(K_{\mathrm{C} \|}, K_{\mathrm{C}_{\perp}}\right.$, Table 3). Three different groups of models considering different contact stiffness are also calculated and denoted as $R, L$ and $H$. The first group R represents the models with "rigid" contact interface with the stiffness equal to $1.5 \cdot 10^{4} \mathrm{~N} \cdot \mathrm{mm}^{-3}$, as was already explained. The second group $L$ are the models with elastic behaviour of the contact interface and the contact stiffness for intermediate angles of the surface normal and the grain direction $\left(0^{\circ}-90^{\circ}\right)$ is calculated using linear interpolation between the stiffness for parallel and perpendicular direction. The third group $\mathrm{H}$ is like the group $\mathrm{L}$, but the contact stiffness for intermediate angles of the surface normal and the grain direction $\left(0^{\circ}-90^{\circ}\right)$ is calculated using the Hankinson's formula:

$$
K_{C, \alpha}=\frac{K_{C, 0} K_{C, 90}}{K_{C, 0} \sin ^{2} \alpha+K_{C, 90} \cos ^{2} \alpha} .
$$

Table 4: Parametric study, description of models and parameters.

\begin{tabular}{|c|c|c|c|}
\hline FEM model & R1 & R2 & R3 \\
\hline \multirow{2}{*}{ Contact surfaces } & $1 \mathrm{a}, 2$ & $1 a, 1 b, 2,3$ & $1 \mathrm{a}, 1 \mathrm{~b}, 1 \mathrm{c}$ \\
\hline & & & $2,3,4$ \\
\hline Contact behaviour & \multicolumn{3}{|c|}{ Rigid, Contact stiffness $=1.5 .10^{4} \mathrm{~N} \cdot \mathrm{mm}^{-3}$} \\
\hline FEM model & L1 & L2 & L3 \\
\hline \multirow{2}{*}{ Contact surfaces } & $1 \mathrm{a}, 2$ & $1 a, 1 b, 2,3$ & $1 \mathrm{a}, 1 \mathrm{~b}, 1 \mathrm{c}$ \\
\hline & & & $2,3,4$ \\
\hline Contact behaviour & \multicolumn{3}{|c|}{ Elastic, Linear interpolation } \\
\hline FEM model & H1 & $\mathrm{H} 2$ & H3 \\
\hline \multirow{2}{*}{ Contact surfaces } & $1 \mathrm{a}, 2$ & $1 a, 1 b, 2,3$ & $1 \mathrm{a}, 1 \mathrm{~b}, 1 \mathrm{c}$, \\
\hline & & & $2,3,4$ \\
\hline Contact behaviour & \multicolumn{3}{|c|}{ Elastic, Hankinson's formula } \\
\hline
\end{tabular}



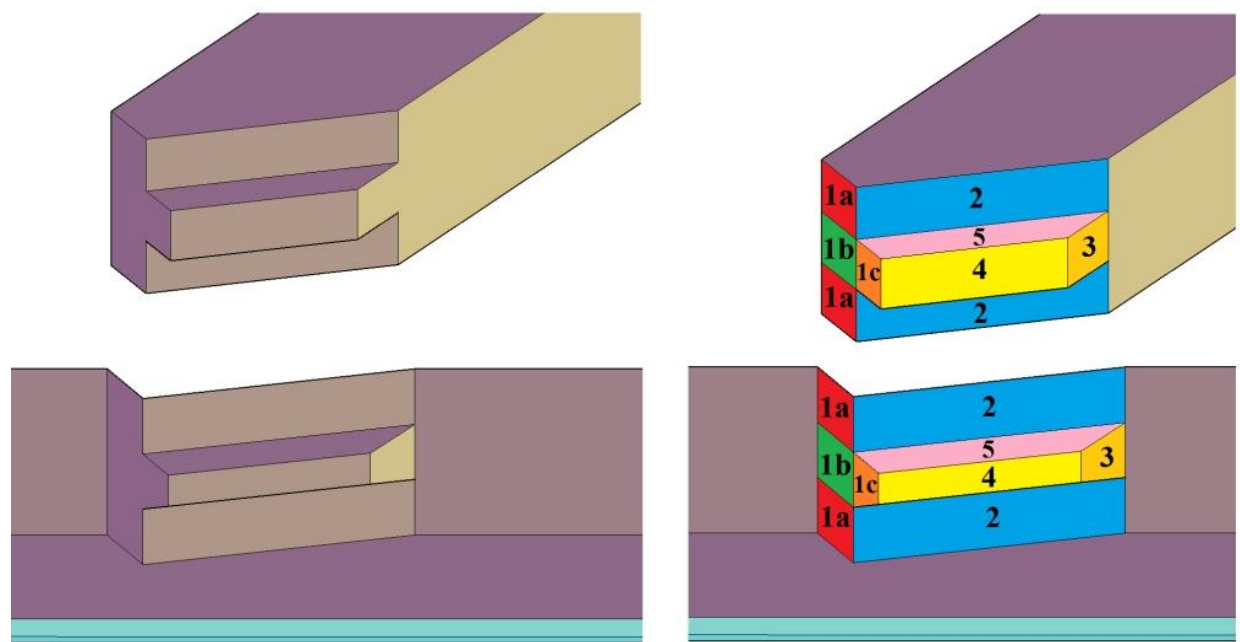

Fig. 4: Surfaces numbers in contact interface.

The relationships between the contact stiffness and the load-to-grain angle are shown in Fig. 5 . The values of the contact stiffness calculated for particular contact surface are presented in Table 5 . The contact zone stiffness corresponding to the brace surfaces and the rafter surfaces is used for calculation of the normal contact stiffness inputted in the numerical model for particular contact interface by equation:

$K_{\text {Contact }, \alpha}=\frac{K_{C, \alpha, \text { Brace }} K_{C, \alpha, \text { Rafter }}}{K_{C, \alpha, \text { Brace }}+K_{C, \alpha, \text { Rafter }}}$.

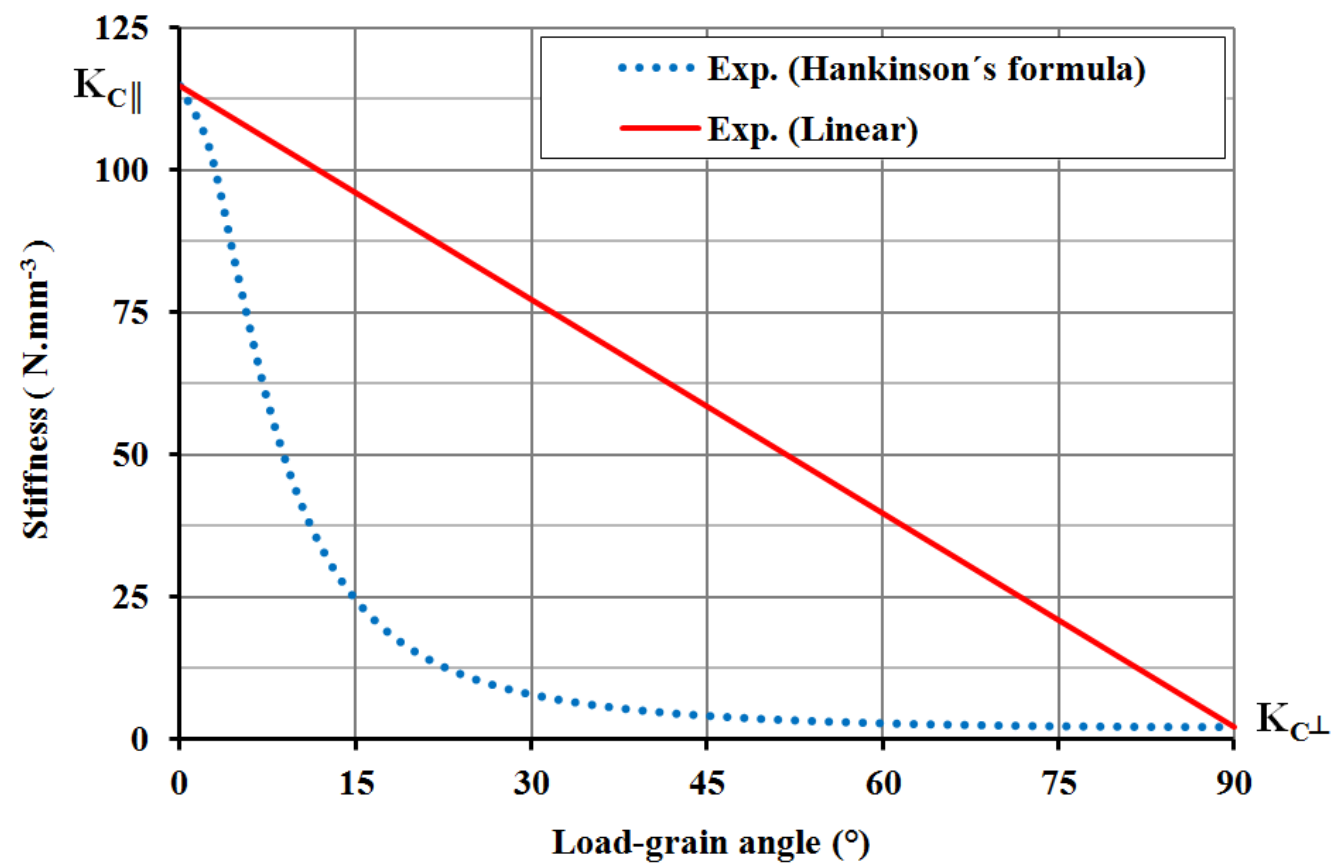

Fig. 5: Relationship between the contact zone stiffness and the load-grain angle. 
Table 5: Parametric study - contact zone stiffness for contacts, $\mathrm{K}_{\text {Contact, } \alpha \text {. }}$

\begin{tabular}{|c|c|c|c|c|c|c|c|c|c|}
\hline \multirow{3}{*}{ 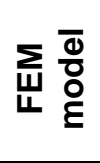 } & \multirow{3}{*}{$\begin{array}{c}\text { Surface No. } \\
\qquad \alpha\left({ }^{\circ}\right)\end{array}$} & & $1 a$ & 1b & $1 c$ & 2 & 3 & 4 & 5 \\
\hline & & Brace & 45.0 & 45.0 & 45.0 & 45.0 & 90 & 45 & 90 \\
\hline & & Rafter & 20 & 20 & 20 & 70 & 25 & 70 & 90 \\
\hline \multirow{4}{*}{$\begin{array}{l}m \\
\text { ỹ } \\
\tilde{y}\end{array}$} & Calculation & & & & \multicolumn{5}{|c|}{$\left(\mathrm{N} \cdot \mathrm{mm}^{-3}\right)$} \\
\hline & expression & Brace & 58.36 & 58.36 & 58.36 & 58.36 & 2.04 & 58.36 & 2.04 \\
\hline & Linear & Rafter & 89.65 & 89.65 & 89.65 & 27.07 & 83.40 & 27.07 & 2.04 \\
\hline & interpolation & Contact & 35.35 & 35.35 & 35.35 & 18.49 & 1.99 & 18.49 & 1.02 \\
\hline \multirow{4}{*}{$\begin{array}{l}\frac{m}{I} \\
\hat{x} \\
\underline{\Sigma}\end{array}$} & Calculation & & & & \multicolumn{5}{|c|}{$\boldsymbol{K}_{\mathrm{c}, \boldsymbol{\alpha}} \quad\left(\mathrm{N} \cdot \mathrm{mm}^{-3}\right)$} \\
\hline & expression & Brace & 4.00 & 4.00 & 4.00 & 4.00 & 2.04 & 4.00 & 2.04 \\
\hline & Hankinson & Rafter & 15.36 & 15.36 & 15.36 & 2.30 & 10.55 & 2.30 & 2.04 \\
\hline & formula & Contact & 3.18 & 3.18 & 3.18 & 1.46 & 1.71 & 1.46 & 1.02 \\
\hline
\end{tabular}

The results of parametric study by means of numerical modelling are presented in Table 6 and Fig. 6 including their comparison to experimental results adopted from [6]. The comparison of the joint stiffness calculated from numerical models to the stiffness obtained experimentally [6] is presented in Fig. 7.

Table 6: Parametric study - the results of joint stiffness (measuring position P1).

\begin{tabular}{|c|c|c|c|}
\hline Experimental $\left(\mathrm{kN} \cdot \mathrm{mm}^{-1}\right)$ & \multirow{2}{*}{\multicolumn{3}{|c|}{30}} \\
\hline Feio, 2005 & & & \\
\hline FEM model & R1 & $\mathbf{R 2}$ & R3 \\
\hline Joint stiffness $\left(\mathrm{kN} \cdot \mathrm{mm}^{-1}\right)$ & 86.10 & 93.47 & 108.96 \\
\hline Ratio: R1 / R2, R3 / R2 (\%) & 92.1 & 100.0 & 116.6 \\
\hline Ratio: R / Exp. (\%) & 287.0 & 311.6 & 363.2 \\
\hline FEM model & L1 & L2 & L3 \\
\hline Joint stiffness $\left(\mathrm{kN} \cdot \mathrm{mm}^{-1}\right)$ & 37.29 & 40.99 & 45.55 \\
\hline Ratio: L1 / L2, L3 / L2 (\%) & 91.0 & 100.0 & 111.1 \\
\hline Ratio: L / Exp. (\%) & 124.3 & 136.6 & 151.8 \\
\hline FEM model & H1 & $\mathrm{H} 2$ & H3 \\
\hline Joint stiffness $\left(\mathrm{kN} \cdot \mathrm{mm}^{-1}\right)$ & 9.86 & 11.92 & 15.02 \\
\hline Ratio: H1 / H2, H3 / H2 (\%) & 82.7 & 100.0 & 126.0 \\
\hline Ratio: H / Exp. (\%) & 32.9 & 39.7 & 50.1 \\
\hline
\end{tabular}

Comparing the results it may be seen that the stiffness calculated for the "rigid" contact interface is approximately three times higher than the experimental joint stiffness. The joint stiffness calculated using the linear interpolation is approximately 1.4-times higher than the experimental stiffness. The results calculated using the Hankinson's formula are only $40 \%$ of the experimental value. The effect of different contact surfaces (Fig. 6, Fig. 7) acting in connection (index numbers of models) is considerable; however, it is very low in comparison with the influence of the contact stiffness.

A comparison of the load-displacement curves calculated from particular numerical model for positions $\mathrm{P} 1$ and $\mathrm{P} 2$ are presented in Fig. 6. As explained before, the position $\mathrm{P} 1$ is located on the brace member and position P2 on the rafter member. Displacements of point P2 are caused by the displacements in the contact between the rafter and the steel plate support, and by deformations of wood of the rafter. Displacements of point P1 are displacements corresponding to point P2 plus the displacements in contact between the brace and the rafter and deformations of rafter.

In Fig. 7, three different groups of the results are shown. The first and the second group represent the results of the experimental test of traditional carpentry joint and the results of numerical 
model, respectively, both presented by (Feio) [6]. The third group shown in Fig. 7 represents the results of numerical model presented in this paper. As presented by (Feio) [6], the mark in figures stiffness " $K_{\text {infinite }}$ " represents the result of the numerical model with the infinite stiffness of the contact interface. Comparing the numerical models developed by [6] to the models presented in this paper, very good match is observed in the case of models with the "rigid" contact interface. The maximum horizontal reaction calculated for the elastic support is $0.68 \mathrm{kN}$ when the maximum applied vertical load was equal to $97.5 \mathrm{kN}$.
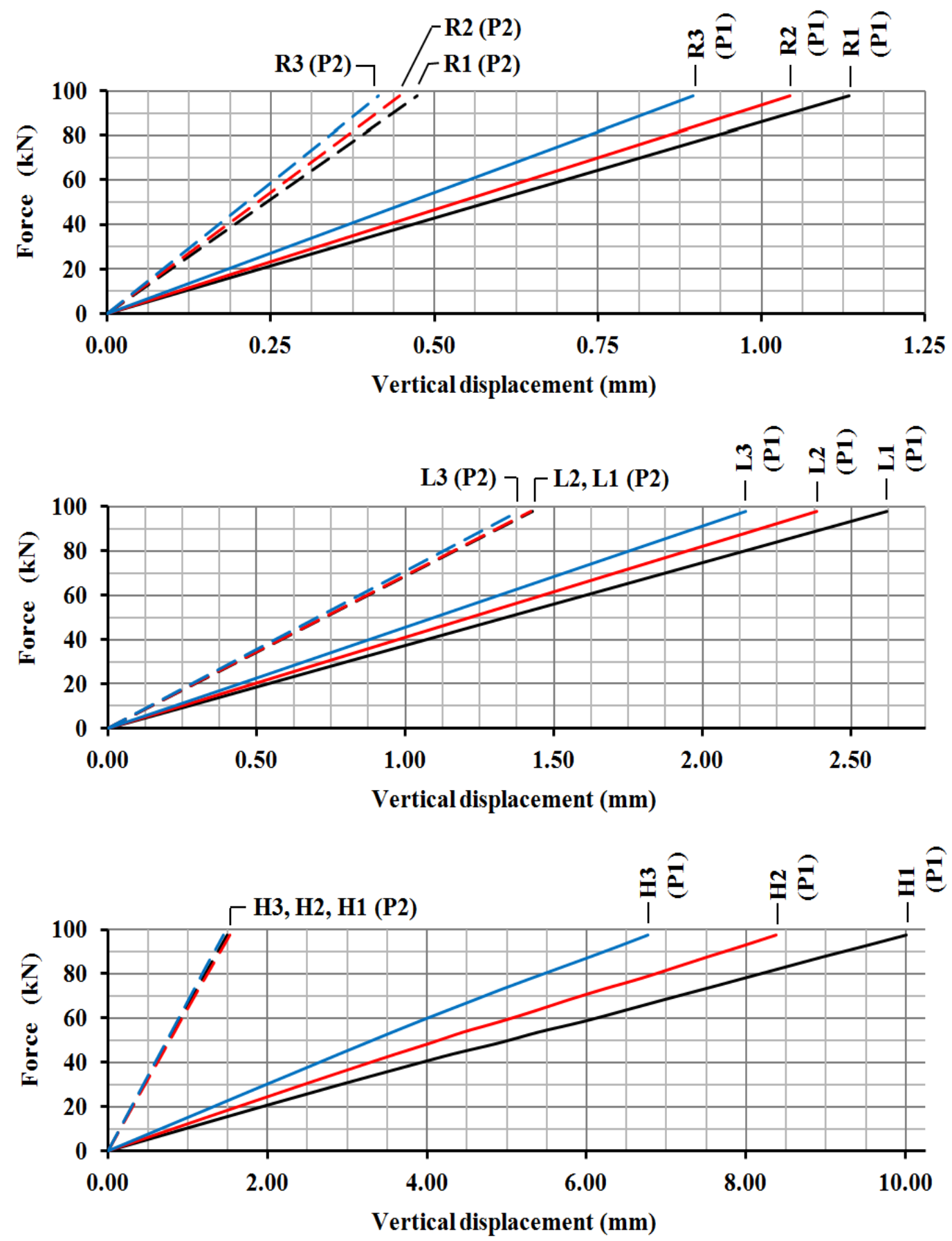

Fig. 6: Parametric study - the load vs. vertical displacement curves. 

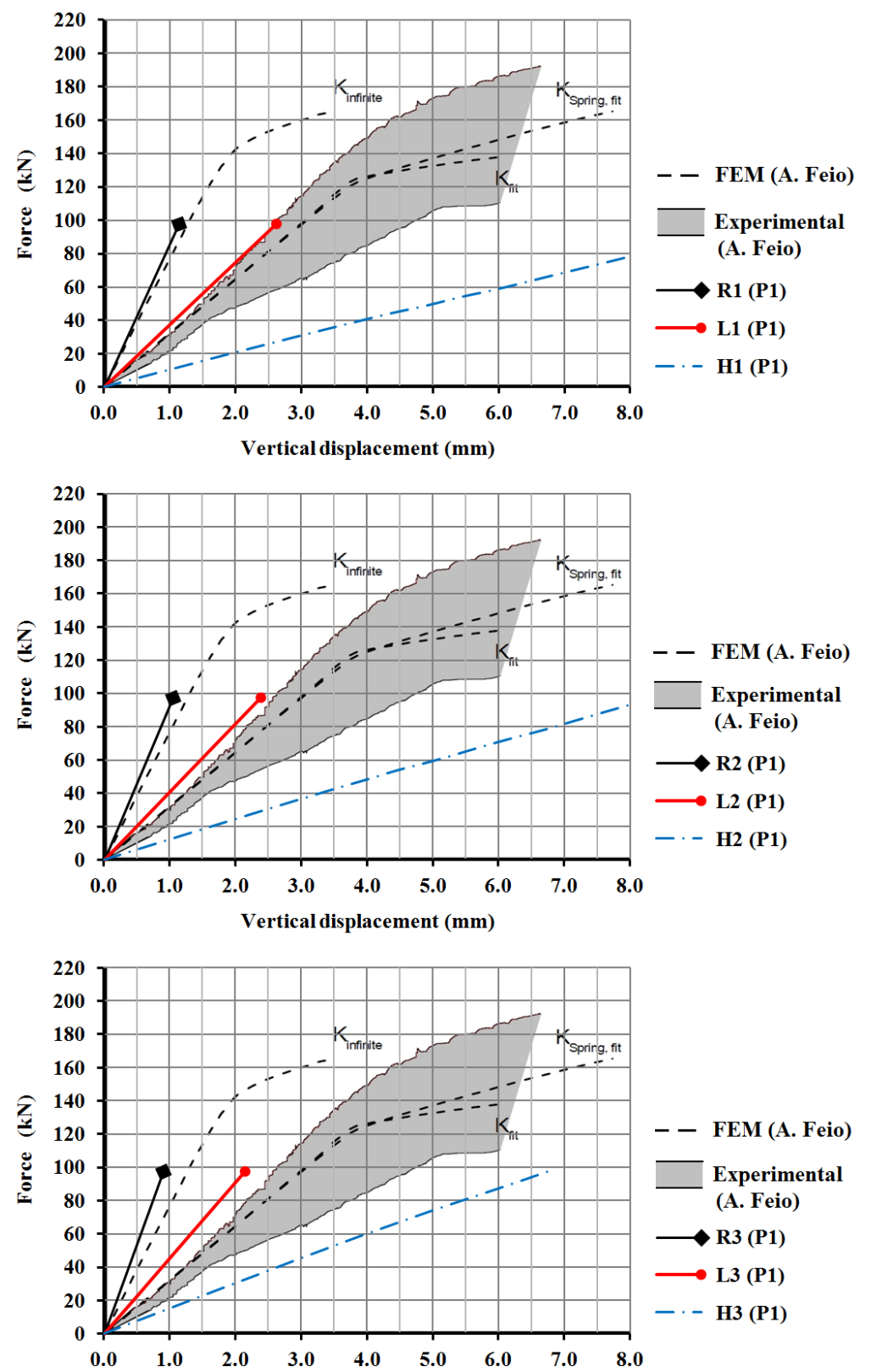

Fig. 7: Parametric study - comparison of the FEM to experimental results [6].

Displacements in vertical direction caused by the contact between the rafter and brace in the carpentry connection are approximately equal to difference between the displacements of point $\mathrm{P} 1$ and P2. In the case of the models with rigid contact interface (models "R"), the displacements occurred in the contact between the brace and rafter are approximately equal to $0.5-0.7 \mathrm{~mm}$, what is $50-60 \%$ of the total displacements calculated in the point P1. In case of the models "L", the displacements occurred in the contact between the brace and rafter are higher due to the softer contact behavior. They are approximately equal to $0.8-1.2 \mathrm{~mm}$, what is $35-45 \%$ of the total displacements calculated in the point P1. For the models "H", with the lowest values of normal contact stiffness inputted for the contact interface, the displacements occurred in the contact between the brace and rafter are approximately equal to $5.0-8.5 \mathrm{~mm}$, what is $80-85 \%$ of total displacements calculated in point P1. As could be expected, the difference between displacements of points $\mathrm{P} 1$ and P2 increases with the decreasing contact stiffness.

Comparing the difference between displacements of points $\mathrm{P} 1$ and $\mathrm{P} 2$ with the total displacements in point $\mathrm{P} 1$, it can be seen the influence of the relationship applied for the contact stiffness calculation. This influence is related to the geometry of two different contact interfaces: 
the contact between rafter and brace, and the contact between rafter and supporting steel plate. The angle between the contact surfaces normals and the grain direction are lower in case of the rafterbrace contact surfaces. On applying the linear relationship and the relationship defined by the Hankinson's formula for the calculation of the contact stiffness of the contact surfaces between rafter and brace, the higher contact stiffness is calculated using the linear relationship. On the other hand, equal values of the contact stiffness are calculated for the rafter-steel-plate contact, since the contact surface normal is perpendicular to the grain direction. Consequently, the ratio of the displacements caused by the compression in the rafter-brace contact surface to the total displacements in point P1 are approximately $35-45 \%$ in case of model "L" and $80-85 \%$ in case of the model "H".

Comparing the displacements presented in Fig. 6 and Fig. 7, it is indicated that the normal contact stiffness may be calculated according to the relationship, which curve should probably fit between the linear and Hankinson's curve in Fig. 5.

As already mentioned, comparing the value of contact zone stiffness evaluated from the experimental [7] tests to the load-displacement relationships determined from the compression tests perpendicular to the grain presented in literature [10] [11], an influence of the surface roughness and unevenness on the experimental results is indicated. The value of contact zone stiffness equal to approximately $2 \mathrm{~N} \cdot \mathrm{mm}^{-3}$ supposedly results from the non-uniform stress distribution on the specimens surfaces as a consequence of the surface roughness and unevenness contrary to the assumption of evaluation model, which has the whole area of specimen's contact surface is uniformly loaded and deformed. This difference indicates the necessity to determine the stiffness behaviour of the wood contact on specimens loaded locally at relatively small area.

Table 7: Side hardness of wood and Hardness modulus, selected results.

\begin{tabular}{|c|c|c|c|c|c|c|c|c|c|}
\hline \multirow{2}{*}{$\begin{array}{l}\text { Wood } \\
\text { species }\end{array}$} & \multirow{2}{*}{$\begin{array}{c}\text { MOC } \\
\%\end{array}$} & \multirow{2}{*}{$\begin{array}{c}\text { Specific } \\
\text { gravity }\end{array}$} & \multirow{2}{*}{ Loading } & \multicolumn{3}{|c|}{ Janka-ball hardness } & \multicolumn{2}{|c|}{$\begin{array}{l}\text { Hardness } \\
\text { modulus }\end{array}$} & \multirow{2}{*}{$\begin{array}{c}\frac{\text { Stiffness }}{\mathrm{K}} \\
\mathrm{N} / \mathrm{mm}^{3}\end{array}$} \\
\hline & & & & Lb. & $\mathbf{N}$ & $\mathrm{MPa}$ & Lb./in. & $\mathrm{N} / \mathrm{mm}$ & \\
\hline \multirow{2}{*}{ Redwood } & \multirow{2}{*}{7.2} & \multirow{2}{*}{0.34} & $\mathrm{~T}$ & 410 & 1824 & 18.2 & 2240 & 392 & 8.7 \\
\hline & & & $\mathrm{R}$ & 430 & 1913 & 19.1 & 2270 & 398 & 8.8 \\
\hline \multirow{2}{*}{$\begin{array}{l}\text { Douglas- } \\
\text { fir }\end{array}$} & \multirow{2}{*}{10.4} & \multirow{2}{*}{0.48} & $\mathrm{~T}$ & 740 & 3292 & 32.9 & 4180 & 732 & 16.3 \\
\hline & & & $\mathrm{R}$ & 720 & 3203 & 32.0 & 3640 & 637 & 14.2 \\
\hline \multirow{2}{*}{ Red Oak } & \multirow{2}{*}{9.2} & \multirow{2}{*}{0.60} & $\mathrm{~T}$ & 1070 & 4759 & 47.6 & 5030 & 881 & 19.6 \\
\hline & & & $\mathrm{R}$ & 1460 & 6494 & 64.9 & 9060 & 1587 & 35.3 \\
\hline
\end{tabular}

As presented by the authors, the penetrations of $0.10 \mathrm{inch}(2.54 \mathrm{~mm})$ are sufficient to determine the slope of this straight-line portion of the curve. The slope of the straight-line portion of the loadindentation curve was determined near the penetration of $2.54 \mathrm{~mm}$ and was used for evaluation of the hardness modulus. Selected results adopted from the research report are presented in Table 7, where the original characteristics evaluated in imperial units are converted into metric units. Since the elastic response was evaluated as a relationship between the force and indentation (hardness modulus), the hardness modulus $(\mathrm{N} / \mathrm{mm})$ is used here for calculation of the stiffness $\mathrm{K}$ dividing by the contact area $\left(\mathrm{mm}^{2}\right)$ resulting from the Hertzian theory of elastic contact. The radius "a" defining the circular contact area is assumed in the calculation, as shown in Fig. 8. The relationship between the Janka hardness and the hardness modulus based on results of the tests presented by the authors of the research report, is shown in Fig. 9. The stiffness of spruce wood contact loaded perpendicular to the grain is equal to $8.5 \mathrm{~N} . \mathrm{mm}^{-3}$, if the relationship defined in Fig. 9 and the hardness of spruce wood equal to $18 \mathrm{MPa}$ [13] are adopted for calculation. In case of the chestnut wood, the normal contact stiffness for direction perpendicular to the grain is equal to $14.5 \mathrm{~N} \cdot \mathrm{mm}^{-3}$. This value is also calculated using the relationship shown in Fig. 9 assuming the hardness of the chestnut wood equal to $3070 \mathrm{~N}$. The hardness for chestnut wood species is adopted from [14]. 


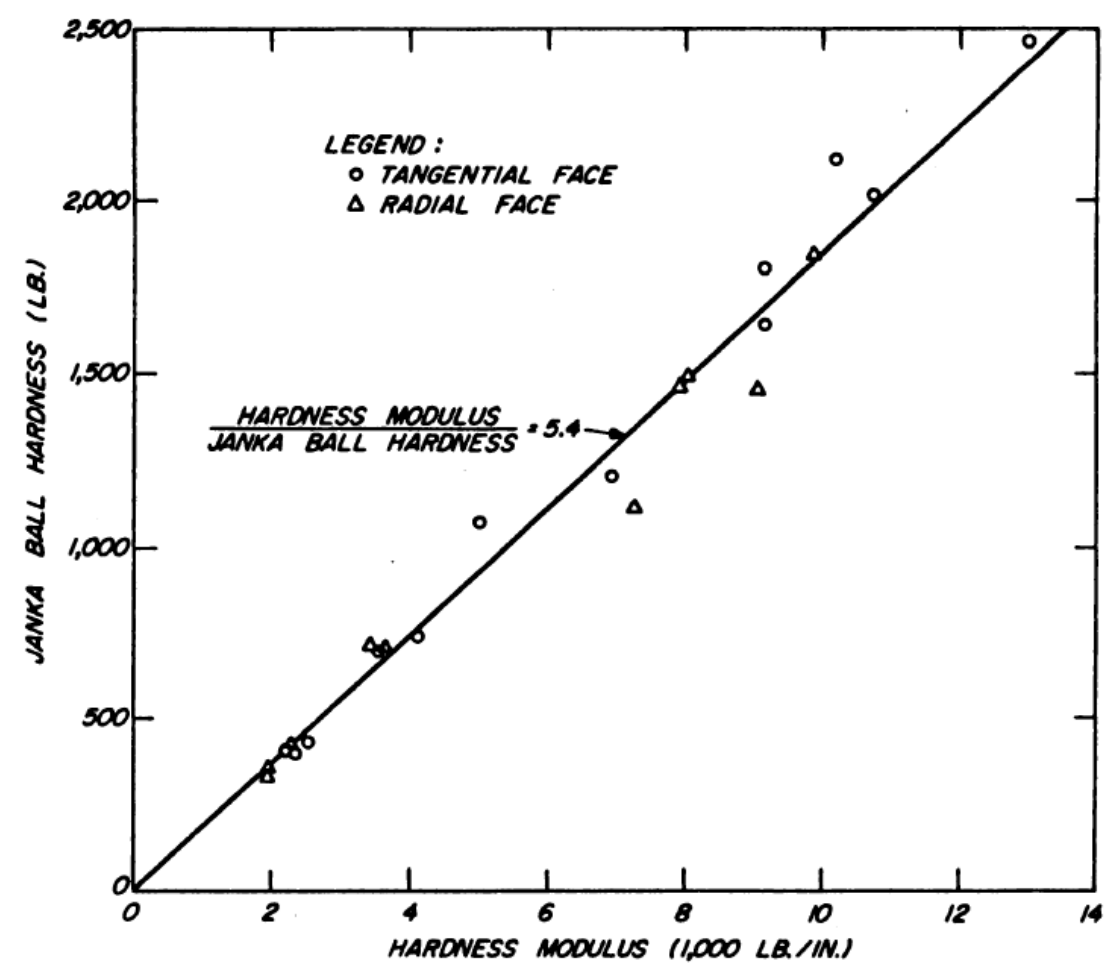

Fig. 8: A rigid sphere in contact with an elastic half-space.

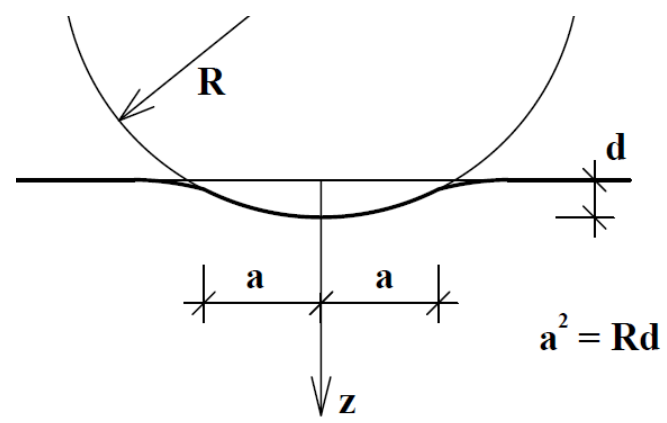

Fig. 9: The relationship between Janka hardness and hardness modulus.

The values of the normal contact stiffness for direction perpendicular to the grain, which were calculated using the relationship between the side hardness of wood and hardness modulus, were adopted in numerical model $\mathrm{H} 2,(\mathrm{H} 2 \mathrm{~b}, \mathrm{H} 2 \mathrm{c})$.

The first value of the normal contact stiffness for direction perpendicular to the grain is equal to $8.5 \mathrm{~N} . \mathrm{mm}^{-3}$, which is adopted in the numerical model "H2b". The second value of the normal contact stiffness for direction perpendicular to the grain is equal to $14.5 \mathrm{~N} . \mathrm{mm}^{-3}$ and it is adopted in the numerical model "H2c". The Hankinson's formula has been used for calculation of the contact stiffness for intermediate angles of the load-to-grain direction between $(0-90)^{\circ}$, as shown in Fig. 10 . The calculated values of the normal contact stiffness, which correspond to particular contact surfaces, are presented in Table 8. The results evaluated from the models " $\mathrm{H} 2 \mathrm{~b}$ " and " $\mathrm{H} 2 \mathrm{c}$ " are presented in Fig. 11 and Fig. 12. 


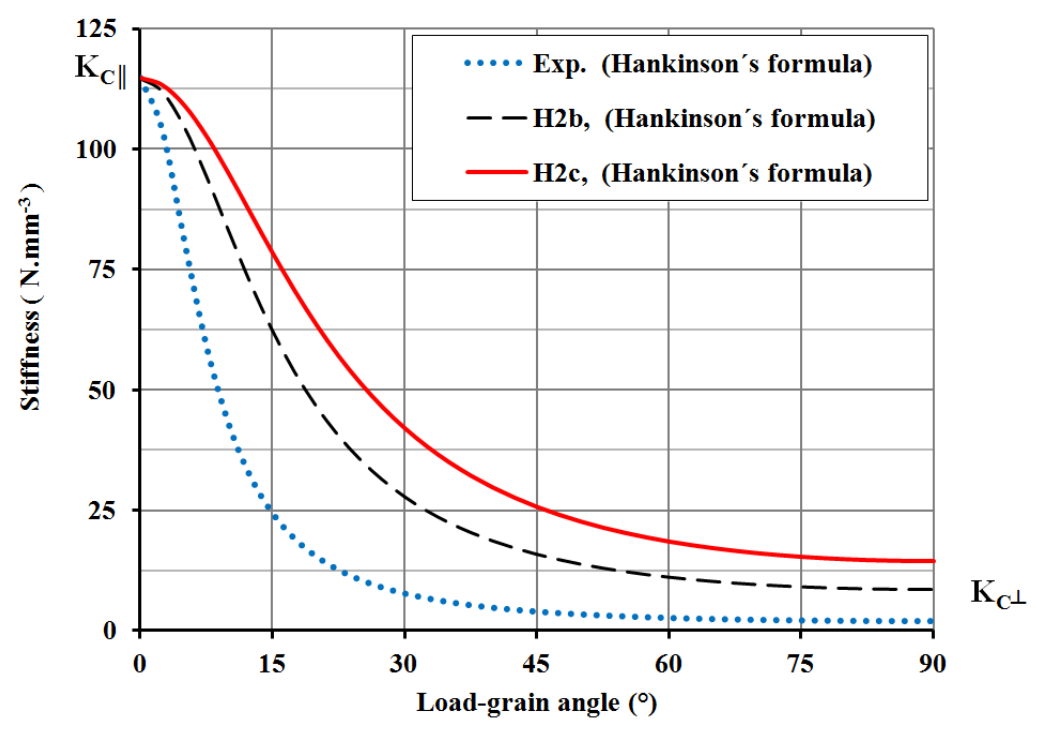

Fig. 10: Numerical model H2b, relationship between the contact zone stiffness and the load-grain angle.

The joint stiffness calculated from the model "H2b" and "H2c" is equal to $33.5 \mathrm{kN} \cdot \mathrm{mm}^{-1}$ and $43.6 \mathrm{kN} \cdot \mathrm{mm}^{-1}$, respectively. Comparing the calculated stiffness from the model "H2b"; to the experimental stiffness presented by (Feio) [6], a very good match is obtained. The joint stiffness calculated from the model "H2c" is 1.45-times higher than the experimental stiffness. For the model "H2b", the displacement that occurred in the contact between the brace and rafter is $73 \%$ of the total displacements calculated in point $\mathrm{P} 1$. In the case of model "H2c", the displacement that occurred in the contact between the brace and rafter is $70 \%$ of the total displacements calculated in point $\mathrm{P} 1$. Considering the initial joint stiffness $\left(0.1 \sim 0.4 F_{\max }\right)$ and the higher joint stiffness obtained after unloading and reloading, what is commonly observed for timber joints due to consolidation of wood in the contact, the joint stiffness calculated from the model " $\mathrm{H} 2 \mathrm{c}$ " is not observed as a huge difference.

Table 8: Numerical models $\mathrm{H} 2 \mathrm{~b}, \mathrm{H} 2 \mathrm{c}$ - numerical inputs for contact interface.

\begin{tabular}{|c|c|c|c|c|c|c|c|}
\hline \multirow{3}{*}{ 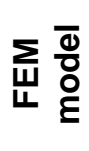 } & \multirow{3}{*}{$\begin{array}{c}\text { Surface No. } \\
\qquad \alpha\left({ }^{\circ}\right)\end{array}$} & & $1 a$ & $1 b$ & 1c & 2 & 3 \\
\hline & & Brace & 45.0 & 45.0 & 45.0 & 45.0 & 90 \\
\hline & & Rafter & 20 & 20 & 20 & 70 & 25 \\
\hline \multirow{4}{*}{$\begin{array}{l}\text { ิㅗ } \\
\text { }\end{array}$} & \multirow{4}{*}{$\begin{array}{c}\text { Calculation } \\
\text { expression } \\
\text { Hankinson's } \\
\text { formula }\end{array}$} & & & $K_{\mathrm{c}, \alpha}$ & \multicolumn{2}{|c|}{$\left(\mathrm{N} \cdot \mathrm{mm}^{-3}\right)$} & \\
\hline & & Brace & 15.83 & 15.83 & 15.83 & 15.83 & 8.50 \\
\hline & & Rafter & 46.60 & 46.60 & 46.60 & 9.53 & 35.49 \\
\hline & & Contact & 11.81 & 11.81 & 11.81 & 5.95 & 6.86 \\
\hline \multirow{4}{*}{ 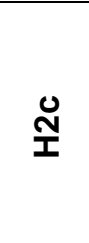 } & \multirow{4}{*}{$\begin{array}{c}\text { Calculation } \\
\text { expression } \\
\text { Hankinson's } \\
\text { formula }\end{array}$} & & & $K_{\mathrm{C}, \alpha}$ & \multicolumn{2}{|c|}{$\left(\mathrm{N} \cdot \mathrm{mm}^{-3}\right)$} & \\
\hline & & Brace & 25.75 & 25.75 & 25.75 & 25.75 & 14.50 \\
\hline & & Rafter & 63.42 & 63.42 & 63.42 & 16.15 & 51.34 \\
\hline & & Contact & 18.31 & 18.31 & 18.31 & 9.92 & 11.31 \\
\hline
\end{tabular}

In order to verify the influence of the contact stiffness in direction parallel to the grain on the carpentry joint stiffness, two additional calculations of the numerical model " $\mathrm{H} 2 \mathrm{~b}$ " have been performed. In the first additional calculation of the model "H2b", the contact stiffness was assumed as double, equal to $229.5 \mathrm{~N} . \mathrm{mm}^{-3}$, and the joint stiffness was increased only by $3 \%$. In the second additional calculation of the model "H2b", the contact stiffness was adopted with half value, equal to $57.3 \mathrm{~N} . \mathrm{mm}^{-3}$, and the joint stiffness was decreased only by $4 \%$. The influence is very low and relates 
to the relationship adopted for calculation of the contact stiffness for the intermediate angles $(0-90)^{\circ}$ as the angle between the normal of the contact surface and the wood grain direction is relatively high for most surfaces; the lowest is equal to $20^{\circ}$.

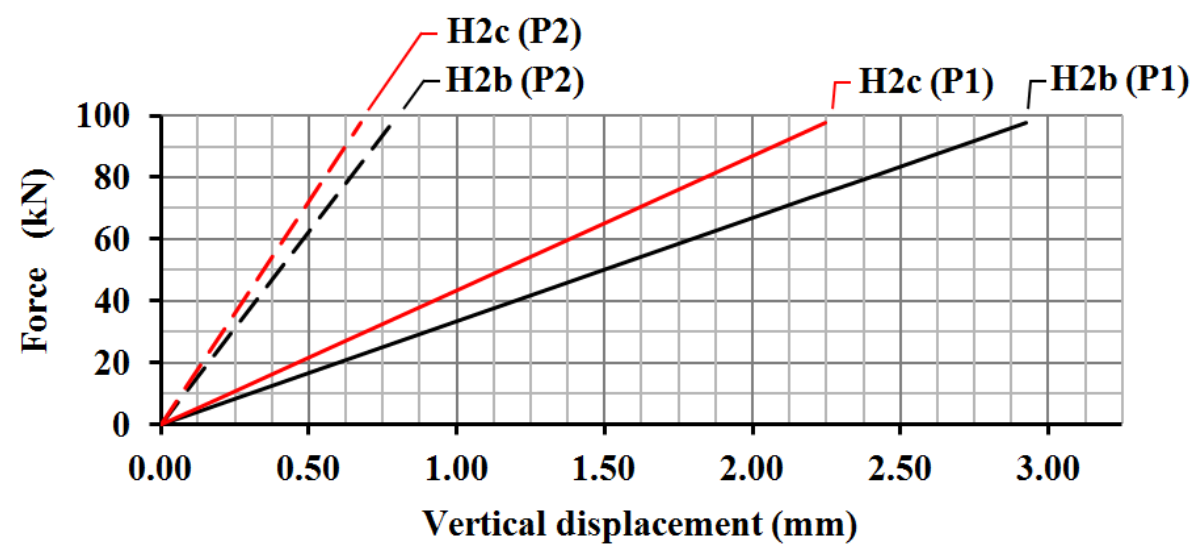

Fig. 11: Numerical model $\mathrm{H} 2 \mathrm{~b}$ - the load vs. vertical displacement curves.

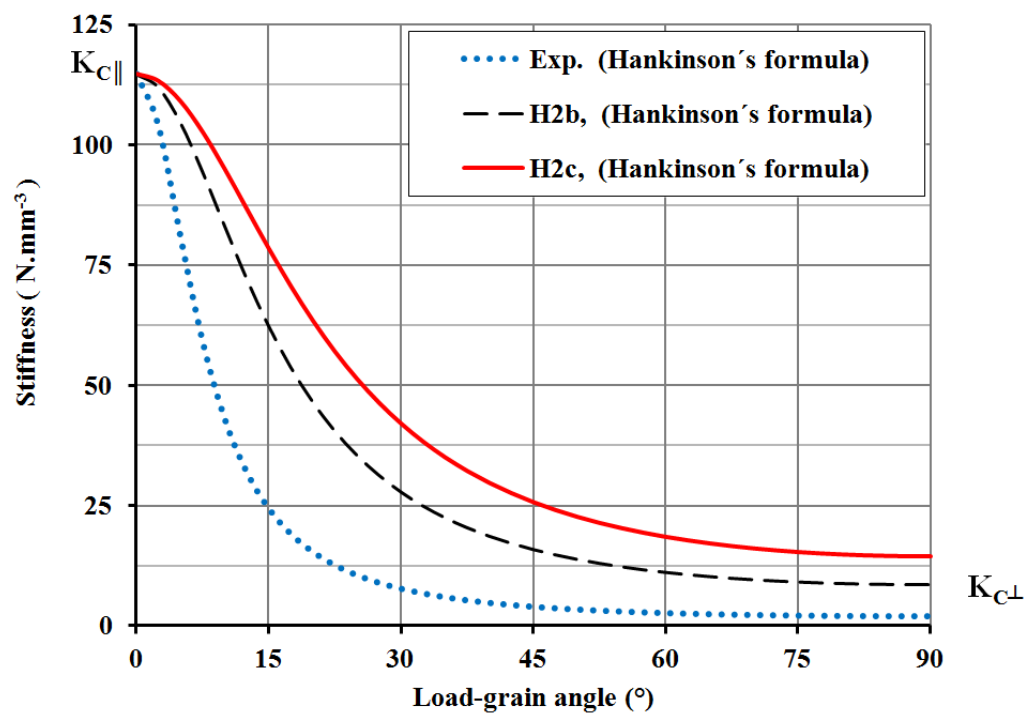

Fig. 12: Comparison of FEM model "H2b" to experimental results [4].

Summarizing the presented numerical analysis and the case study of the experimental tests of traditional carpentry joint, a significant sensitivity of the joint stiffness on the contact stiffness adopted in calculation is obtained. The rigid contact behaviour adopted in calculations resulted in more than triple stiffness of the carpentry joint comparing to the experimental joint stiffness. The results obtained from numerical modelling showed good match, when the elastic contact interface was adopted and the contact stiffness for perpendicular to the grain direction obtained experimentally was increased.

\section{Conclusions}

To approximate the load-displacement behaviour of the wood specimens tested during the experimental investigation, the numerical modelling was performed. Numerical models of the wood specimens were created using the contact elements for approximation of its stiffness. The applied modelling method establishes the contact between two surfaces by elastic springs with the stiffness called the contact stiffness. Comparison of the calculated results and the experimentally determined results has shown a good agreement. 
The experimental test of traditional carpentry joint was presented as the case study. The elastic stiffness of traditional carpentry joint was the scope of the numerical modelling and no failure criteria was adopted into the model. The values of contact stiffness adopted in the numerical model have been determined during the experimental investigation. The results obtained from numerical models have shown significant sensitivity of the joint stiffness on the stiffness of the contact interface adopted in calculation. The calculated displacements for the contact between timber members in carpentry connection represented more than a half of the total displacements of carpentry joint. Comparison between the presented models and models presented by (Feio, 2005) [6] showed almost equal joint stiffness when the "rigid" contact interface was adopted in the model. The joint stiffness calculated adopting the "rigid" contact interface is significantly higher compared to the results presented in the case study (Feio, 2005) [6]. Significantly low value of the contact stiffness for the perpendicular to the grain direction has been obtained during the experimental investigation. It obviously resulted in low stiffness calculated by numerical model.

For this reason, the stiffness of wood contact loaded perpendicular to the grain based on hardness modulus was introduced in numerical models. The relationship between the hardness modulus and the Janka hardness according to [12] was adopted for calculation of the contact stiffness in perpendicular to the grain direction. The results obtained from numerical modelling using these values of the contact stiffness in the perpendicular to the grain direction provided a good agreement with the experimental results [6].

\section{Acknowledgement}

The paper was prepared with the support of the Scientific Grant Agency of the Slovak Republic within the solution of project 1/0257/14 "Real behaviour of joints of combined timber-steel bridges."

\section{References}

[1] EN 1995-1-1:2004/A1:2008: Eurocode 5: Design of timber structures - Part 1-1: General Common rules and rules for buildings.

[2] PIAZZA, M. - CANDELPERGHER, L.: Mechanics of traditional connections with metal devices in timber roof structures. In Proceedings of the $7^{\text {th }}$ Int. Conf. STREMAH. Bologna, Italy, 2001, pp. 415-424.

[3] PALMA, P. - CRUZ, H.: Mechanical behaviour of traditional timber carpentry joints in service conditions-results of monotonic tests. In From material to structure, Mechanical behaviour and failures of the timber structures, ICOMOS IWC-XVI International Symposium. Florence, Venice and Vicenza, Italy, 2007.

[4] BRANCO, J. M.: Influence of the joints stiffness in the monotonic and cyclic behaviour of traditional timber trusses. Assessment of the efficacy of different strengthening techniques: Doctoral thesis. University of Minho and University of Trento. Portugal, Italy, 2008.

[5] DESCAMPS, T. - LEMLYN, P.: Effects of the rotational, axial and transversal stiffness of the joints on the static response of old timber framings. In Proceedings of the International Conference on the Protection of Historical Buildings. Rome, Italy, 2009, pp. 281-286.

[6] FEIO, A. O.: Inspection and diagnosis of historical timber structures: NDT correlations and structural behaviour. Doctoral thesis. University of Minho, Portugal, 2005.

[7] KEKELIAK, M.: Stiffness of carpentry connections. Proceedings of conference HISTORICKÉ KROVY 2014. (In print).

[8] FEIO, A. - MACHADO, J. S.: Traditional timber carpentry joints: monotonic tests and modelling.: COST FP1004, Experimental Research with Timber, May 21-23, 2014, Prague, Czech Republic. Schober, K.U., University of Bath, United Kingdom, 2014. 218p.

[9] ANSYS ${ }^{\circ}$, Academic Research, Release 12.0. 2009. ANSYS, Inc. Documentation for Release 12.0.

[10]BLASS, H. J. - GÖRLACHER, R.: Compression perpendicular to the grain. In Proceedings of the 8th World Conference on Timber Engineering WCTE 2004, Vol. 2. Lahti, Finland, 2004, pp. 435440.

[11]KOLLMANN, F.: Principles of wood science and technology, vol. I. Berlin : Springer-Verlag, 1984. 592p. ISBN 3-540-04297-0. 
[12] LEWIS, W. C.: Hardness modulus as an alternate measure of hardness to the standard Janka ball for wood and wood-base materials : Research Note, FPL-0189. USDA Forest Service, Forest Products Laboratory, Madison, Wisconsin, 1968. 13p.

[13]KLEMENT, I. - RÉH, R. - DETVAJ, J.: Základné charakteristiky lesných drevín. NLC Zvolen, 2010, 82p. ISBN 978-80-8093-112-4.

[14]WIEMANN, M. C. - GREEN, D. W.: 2007. Estimating Janka hardness from specific gravity for tropical and temperate species : Research Paper FPL-RP-643. USDA Forest Service, Forest Products Laboratory, Madison, Wisconsin, 2007. 21p.

[15] EC - Certificate of Conformity. 0672-CPD-I 14.21.57, ETA-13/0646 : Glued laminated timber made of hardwood. Materialprüfungsanstalt Universität Stuttgart. 2013.

[16]VEGA, C. A.: Caracterización mecánica de la madera estructural de Castanea sativa Mill. Clasificación visual y evaluación mediante métodos no destructivos: Tesis doctoral. Universidad de Santiago de Compostela. España, 2013.

[17]EN 338:2004: Structural timber. Strength classes. 